\title{
EFFECT OF THE DISTANCES OF PUBLIC HEALTH FACILITIES FROM THE NEAREST MAJOR ROADS ON SKILLED DELIVERIES CONDUCTED IN KISUMU COUNTY, KENYA
}

\author{
K. Rombosia ${ }^{1}$, E. Oele ${ }^{1}$, N Rangara ${ }^{1}$, J. Mwaura ${ }^{2}$, B. Mitto ${ }^{3}$, E. Ondura ${ }^{3}$, D. Onyango ${ }^{1}$, *C. Akoth ${ }^{2,3}$ \\ 1 Kisumu County Department of Health, Kevinrombosia@gmail.com \\ 2 College of Health Sciences Jomo Kenyatta University, Main Campus Juja, Kiambu, Kenya, Carole.akoth@ gmail.com \\ 3 HIGDA, Morning Side Office Park, Nairobi, Kenya Benard.mitto@thepalladiumgroup.com
}

\section{Commission IV and WG IV/4}

KEY WORDS: Universal health Coverage, Health care access, Skilled Delivery, Access to Health, District Health Information System, Electronic Medical Records System.

\begin{abstract}
:
The project sought to describe health facility accessibility and its effect on skilled delivery in Kisumu in line with the pillars of UHC. Proportion of skilled deliveries for 156 public health facilities conducted in 2016 was mined from DHIS2. Healthcare physical services accessibility was represented using a $5 \mathrm{~km}$ radius fixed distance buffering around health facilities and the health facilities' distances to the nearest major roads. Simple linear regression was then done between distances of the health facilities to their nearest major roads and skilled deliveries conducted in the health facilities. The mean skilled delivery was $42.5 \%$ (Median $=45.8 \%$, Range 0 to $358 \%$ and $\mathrm{IQR}=48.6 \%$ ). There exist 4 pockets of underserved areas in Nyando, Nyakach and Muhoroni sub counties measuring $21 \mathrm{kms}^{2}, 52 \mathrm{kms}^{2}, 60 \mathrm{kms}^{2}, 65 \mathrm{kms}^{2}$ and $94 \mathrm{kms}^{2}$ respectively. Distance from the nearest road to skilled deliveries conducted, showed the $\mathrm{R}^{2}$ value was 0.02 . The study found out that underserved areas are located away from major roads. The mean skilled delivery was lower than the national of $65 \%$. However some facilities exceeded $100 \%$. This can be explained by in referrals that cause such facilities to exceed their projected workloads. The distance of a health facility to the nearest major road is inversely proportional to the skilled deliveries conducted meaning that the further a heath facility is from a major road, lesser the skilled deliveries conducted in that facility and vice versa. However, this model is weak in establishing such an effect because of the low $\mathrm{R}^{2}$ value. In conclusion, there are pockets of underserved areas in Kisumu and distance of health facilities from the nearest major road does not significantly affect the conduct of skilled deliveries in Kisumu County.
\end{abstract}

\section{INTRODUCTION}

One of sustainable development goals pillars is the attainment of universal health care (UHC)(WHO, 2017). In 2018, Kisumu County was selected by the Government of Kenya as one of the four counties where universal health care will be piloted. Kisumu County is one of the 47 counties in Kenya, and comprises of 7 Sub counties namely Seme, Kisumu West, Kisumu East, Kisumu Central, Nyando, Muhoroni and Nyakach. Its population is projected to reach $1,163,260$ in 2018 with males and females accounting for $49 \%$ and $51 \%$ respectively and an annual growth rate of 2.8\%(County, 2018).

Key UHC index tracer indicators include the proportion of skilled deliveries conducted and health facilities access(WHO, 2017).

As Kisumu County journeys towards piloting UHC, it is important to understand how the proportion of skilled deliveries conducted is affected by the location of public health facilities. One way in by which access to health facilities can be measured is by measuring their distances to the nearest roads. In determining physical access to healthcare services by using distance from the facility either the straight-line distance, the distance patients have to travel or the distance travelled by patients in a given time, it is assumed that people will visit the closest facility, which implies that distance is the overriding factor influencing attendance(Zinszer, 2014).

\section{BACKGROUND}

Skilled delivery is defined as the conduct of delivery in a health facility and/or by a trained health professional. Skilled delivery is known to improve both maternal and fetal outcomes. Approximately 1000 women die each day worldwide from pregnancy related causes, $99 \%$ of them in developing countries and more than $50 \%$ in sub-Saharan Africa(WHO, 2008).In a study conducted in Burkina Faso, the distance to a health centre was a major determinant of institutional delivery: three quarters $(76.7 \%)$ of births within $1 \mathrm{~km}$ of the health centre took place in a facility, compared with a mere fifth $(18.5 \%)$ for births further than $10 \mathrm{~km}$ from the health centre (Sennen Hounton, 2008). It is crucial that research and policy focus on health system determinants and

* Corresponding Author 
in particular address geographic and quality barriers to obstetric care(Sabine Gabrysch, 2011). This study focuses on using health facilities' distance from the nearest major road as a proxy for accessibility and how this accessibility affects the skilled deliveries conducted.

\section{STATEMENT OF THE PROBLEM}

According to the Kenya Health Sector Strategic and Investment Plan, households should be located within 5 kilometres access to medical services( $\mathrm{MOH}, 2013)$. In Kisumu County, the actual extent of primary healthcare services physical coverage and whether or not underserved pockets exist is not known. It is also not known how location of health facilities by way of their distance from the nearest major roads affects skilled deliveries conducted in Kisumu County in the context of achieving UHC.

This study sought to describe the physical coverage of public healthcare services in Kisumu County and identify any underserved pockets; if they exist. It also sought to analyze the effect of the distance of public health facilities to their nearest major roads on skilled deliveries conducted in order to inform the piloting of UHC in Kisumu County.

If it is established that the distance of a health facility to the nearest road remarkably affects the proportion of skilled deliveries conducted in Kisumu county, it will strongly reinforce the need of policy makers to rapidly improve the transport network of health facilities to the major roads as a means of improving the UHC tracer indicator of proportion of skilled deliveries conducted.

\section{JUSTIFICATION}

There is paucity of information of health access, in the context how far or near a health facility is to a major road, affects health indicators; more specifically, affects the conduct of skilled deliveries. Most studies conducted so far focus on the household's location from their nearest health facility either by way of evaluating how straight line distances from household locations to health facilities affects health indicators.

In a study in Zambia, Sabirne et al used straight line distances form the study clusters to the nearest health center to examine how this affects skilled deliveries conducted. The assumption in the Zambia study, as is, in this study is that people will seek treatment in health facilities that are located closest to them.

Health access improvement can include the construction of more major roads or improving the existing ones and the construction of more health facilities in underserved areas. This study will provide information on how accessibility, as measured by a facility's distance to the nearest major road affects the conduct of skilled deliveries. This information will be useful for policy makers seeking to prioritize interventions for increasing skilled deliveries and hospital access as key tracer indicators for UHC index.
The following was the conceptual framework:

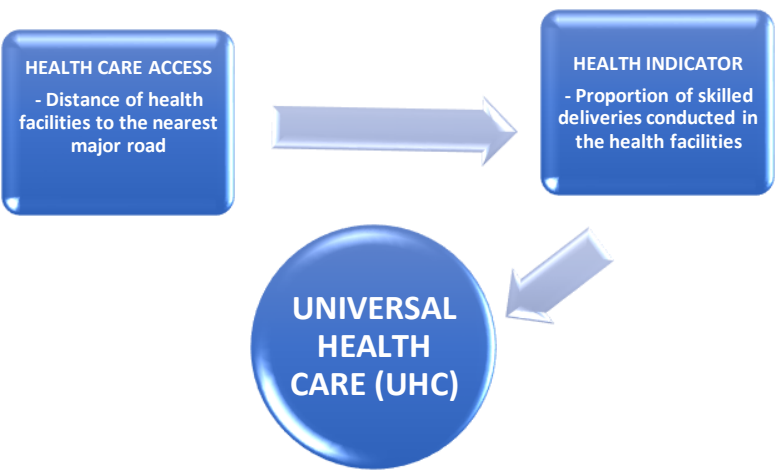

Figure 1: Conceptual framework

\section{RESEARCH QUESTION}

What is the effect of the distances of public health facilities from their nearest major roads to the skilled deliveries conducted in Kisumu County?

\subsection{Broad objective}

To determine the effect of the distances of public health facilities from their nearest major roads to the skilled deliveries conducted in Kisumu County.

\subsection{Specific Objectives}

The specific objectives of the study were:

- To describe public health facilities accessibility in Kisumu County

- To describe the proportion of skilled deliveries conducted in Kisumu County

- To analyze the effect of the distances of public health facilities from their nearest major roads to the skilled deliveries conducted in Kisumu County.

\section{METHODOLOGY}

\subsection{Study Area}

The study included public and semi - public (i.e. faith based and non - government) health facilities in Kisumu County that conduct deliveries. Private facilities were excluded in this study.

\subsection{Study Design}

\section{CONCEPTUAL FRAMEWORK}


The study design was a retrospective chart review. Secondary data (electronic data) was mined from the Kenya District Health Information System (MoH, 2018).

\subsection{Sample Size}

A total of 156 public and semi - public (i.e. faith based and non - government) health facilities in Kisumu County that conduct deliveries were included in the study.

\subsection{Data Collection}

Secondary data (electronic data) was mined from the Kenya District Health Information System database (https://hiskenya.org) (MoH, 2018). The indicator of interest was proportion of skilled deliveries conducted from January to December 2016.

We then obtained a list of public healthcare facilities in Kisumu County from the Kenya Master Facilities List which categorizes health facilities in Kenya by ownership type and level of care.

The health facilities' geo codes were obtained from the Kisumu County health facilities list of geo codes.

\subsection{Data Management and Analysis}

The data was then exported to MS Excel software (Windows 10 version) processing and analysis. MS Excel was used to calculate the range, mean and standard deviation for the proportion of skilled deliveries.

In DHIS, the proportion of skilled deliveries per facility is calculated as follows:

Proportion of skilled deliveries $=$ Number of skilled deliveries conducted $\times 100 \%$

Estimated number of pregnant women in the catchment popula

(1)

The health facilities geo codes were exported to QGIS software (Version 2.18.17). The locations of the health facilities were represented as points. The attribute of the proportion of skilled deliveries conducted was then assigned to each respective health facility.

We represented healthcare services physical coverage using a 5 kilometers radius fixed distance buffering using the health facilities' points as the hubs. We also generated Voronoi polygons to represent coverage.

We were then able to identify underserved areas, defined as geographical areas that are excluded from a 5 kilometers distance to a nearest public healthcare facility in whichever direction.

The distances of the health facilities to the nearest roads was generated using the "Distance to nearest hub" processing tool in QGIS.
We then conducted a simple linear regression of the distances to the nearest roads (predictor variable, $x$ ) and the proportion of skilled deliveries conducted (outcome variable, $y$ ) using STATA software (Version 15).

\subsection{Quality Control}

The data mined from DHIS was examined for completeness. A total of thirteen (13) facilities that had missing data were excluded from the analysis.

\subsection{Ethical Considerations}

Ethical approval was not sought as this study did not involve human subjects.

\subsection{Study Limitations}

This study was restricted to the effect of public and semi public hospitals' distances to the nearest major roads on skilled deliveries conducted. The terrain was not factored in the analysis.

\section{RESULTS}

There is a high concentration of primary healthcare facilities in Kisumu Central, Kisumu West and Seme sub counties. The two comprehensive referral hospitals are all situated in Kisumu Central Sub County.

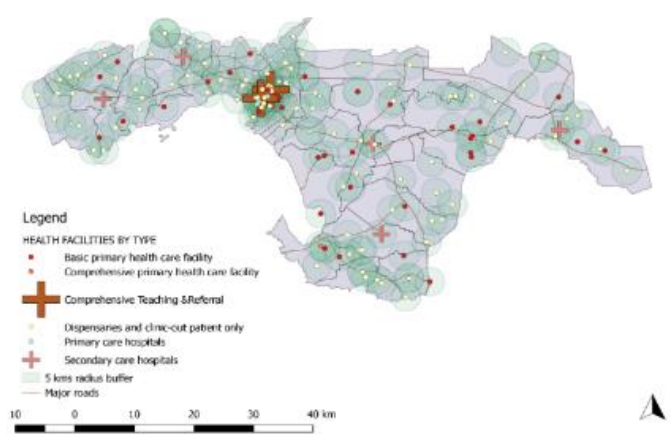

Figure 2: Health facilities by level of care

There exist four pockets of underserved areas in Nyando, Nyakach and Muhoroni sub counties measuring $21 \mathrm{kms}^{2}, 52$ $\mathrm{kms}^{2}, 60 \mathrm{kms}^{2}, 65 \mathrm{kms}^{2}$ and $94 \mathrm{kms}^{2}$.

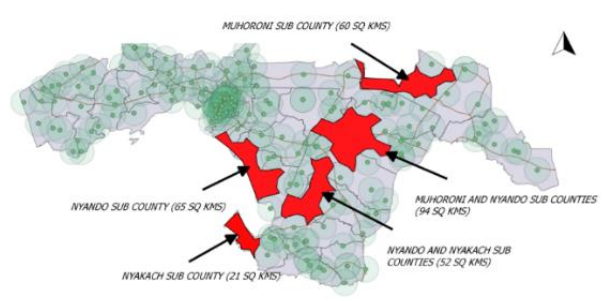


Figure 3: Underserved areas in Kisumu County

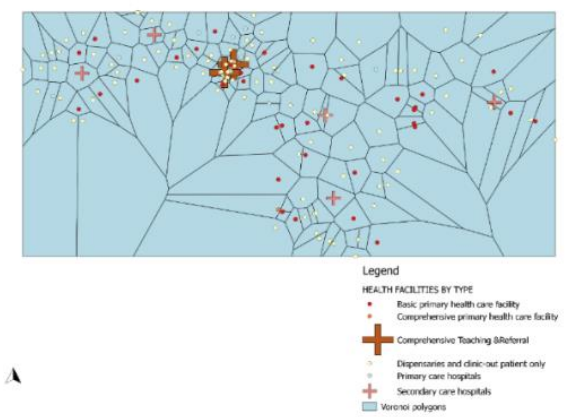

Figure 4: Voronoi polygon on coverage

The mean skilled delivery for the 156 facilities was $42.7 \%$ and the values ranged from 0 to $358 \%$. Standard deviation was 52.1 .

The mean distance of the health facilities from the nearest road was $1.8 \mathrm{kms}$, with a range of $0.1 \mathrm{kms}$ to $9.5 \mathrm{kms}$. The standard deviation was $1.8 \mathrm{kms}$.

\begin{tabular}{|l|l|l|l|l|l|}
\hline Variable & $\begin{array}{l}\text { Obser } \\
\text { vation }\end{array}$ & Mean & Std Dev & Min & Max \\
\hline $\begin{array}{l}\text { \% skilled } \\
\text { deliveries }\end{array}$ & 156 & 42.57429 & 52.083 & 0 & 357.8 \\
\hline $\begin{array}{l}\text { Distance } \\
\text { from } \\
\text { road }\end{array}$ & 156 & 1.849027 & 1.827 & .1371 & 9.495 \\
\hline
\end{tabular}

Table 1: Summary of proportion of skilled deliveries and facilities distances from the nearest roads.

Regarding the linear regression between the health facilities distances from the nearest road (predictor variable, $x$ ) to skilled deliveries conducted (outcome variable, $y$ ), the linear equation obtained was: $y=50.727-4.4089 x$. The coefficient of determination $\left(\mathrm{R}^{2}\right.$ value) was 0.023 . The adjusted $\mathrm{R}$-squared value was 0.018 . The linear equation had a negative slope.

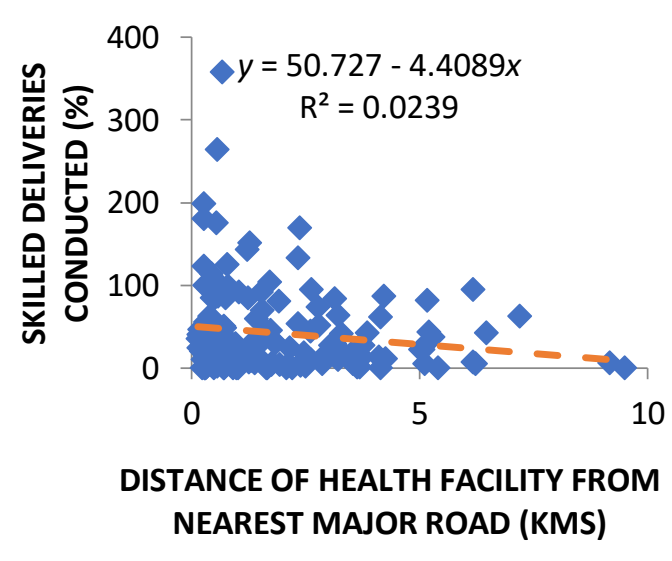

Chart 1: STATA Output: Scatter plot of distance and proportion of skilled deliveries

\begin{tabular}{|l|l|l|l|l|}
\hline $\begin{array}{l}\text { Sourc } \\
\text { e }\end{array}$ & SS & df & MS & $\begin{array}{l}\text { Number of } \\
\text { observations = 156 }\end{array}$ \\
\hline $\begin{array}{l}\text { Mode } \\
\mathbf{l}\end{array}$ & $\begin{array}{l}10062.1 \\
715\end{array}$ & 1 & $\begin{array}{l}10062 . \\
1715\end{array}$ & $\begin{array}{l}\text { Prob > F = 0.0538 } \\
\text { [95\% Conf. Interval }]\end{array}$ \\
\hline $\begin{array}{l}\text { Resid } \\
\text { ual }\end{array}$ & 410395. & 15 & $\begin{array}{l}2664.9 \\
0481\end{array}$ & $\begin{array}{l}\text { R-squared = 0.0239 } \\
\text { Adj R-squared } \\
0.0176\end{array}$ \\
\hline Total & $\begin{array}{l}420457 . \\
513\end{array}$ & 5 & 2712.6 & Root MSE = 51.623 \\
\hline
\end{tabular}

Table 2: STATA Output: Linear regression of distance and proportion of skilled deliveries

\section{DISCUSSION}

The mean distance of the location of health facilities from the nearest major roads was 1.8 kilometers. By using the 5 kilometers radius buffer around health facilities, we established that there are underserved areas in Kisumu County which are mostly located away from major roads and towns. The well served areas are mostly along major roads and towns. The largest of these pockets extends between Nyando and Muhoroni sub counties.

Sabirne et al established in Zambia that the further away a pregnant woman resides from a health facility, the lesser the possibility of accessing skilled delivery services. The assumption in this study, as is in our study, was that a pregnant woman would seek skilled delivery in a health facility located closest to her residence.

In our study, the coefficient of determination, $\mathrm{R}^{2}$ value, using the distance of health facilities from the nearest roads as the predictor variable and the proportion of skilled deliveries as the outcome variable was $2 \%$. This is a low value. This means that whereas distance of a health facility to the nearest major road is inversely proportional to the skilled deliveries conducted as indicated by the negative slope of the linear equation (meaning that the further a facility is located from a major road, the lesser the skilled deliveries conducted in that facility and vice versa), such a model is still weak in establishing such an effect.

However, our study focused on the use of major roads. It did not take into account the use of minor roads and the terrain around the location of the health facilities.

The mean skilled delivery in Kisumu County for the study period was $42.7 \%$, which is lower than the national target of $65 \%$ skilled deliveries conduct $(\mathrm{MOH}, 2013)$. Given that the skilled deliver level in Kisumu County is much lower than the national target, it is possible that there are other factors besides just distance to health facilities. This could include 
the other UHC tracer such as health care worker density, health access by way of ability to pay for transport to the health facilities and the quality of service offered at the health facilities. Future studies ought to investigate these.

Indeed, Kitui et al established that the effect of distance from a health facility was not significant after controlling for other variables. Women most commonly cited distance and/or lack of transport as reasons for not delivering in a health facility but over $60 \%$ gave other reasons including $20.5 \%$ who considered health facility delivery unnecessary, $18 \%$ who cited abrupt delivery as the main reason and $11 \%$ who cited high cost (John Kitui, 2013).

However, some facilities conducted skilled deliveries exceeding the national target. This can be explained by inreferrals that cause such facilities to exceed their projected workloads.

\section{CONCLUSION}

There are pockets of underserved areas in Kisumu County regarding physical access to health care services. The mean skilled delivery in Kisumu County is lower than the national target. The distance of health facilities from the nearest major road does not significantly affect the conduct of skilled deliveries in Kisumu County.

\section{RECOMMENDATIONS}

There is a need to conduct a further study on how RMNCH disease indices, communicable disease indices, communicable disease indices, service capacity and access indices affect the UHC index in Kisumu County.

\section{REFERENCES}

1. County, K. 2018. A concept for universal health coverage in Kisumu. Department of Health.

2. JOHN KITUI, S. L. A. G. D. 2013. Factors influencing place of delivery for women in Kenya: an analysis of the Kenya demographic and health survey, 2008/2009. BMC Pregnancy and Childbirth.

3. MOH 2013. HEALTH SECTOR STRATEGIC AND INVESTMENT PLAN (KHSSP) JULY 2013-JUNE 2017.

4. MOH 2018. District Health Information System. https://hiskenya.org.

5. SABINE GABRYSCH, S. C., JONATHAN COX, OONA M. R. CAMPBELL 2011. The Influence of Distance and Level of Care on Delivery Place in Rural Zambia: A Study of Linked National Data in a Geographic Information System. PLOS Medicine.

6. SENNEN HOUNTON, G. C., JORIS MENTEN, VINCENT DE BROUWERE, TIM ENSOR, ISSIAKA SOMBIE, NICOLAS MEDA AND CARINE RONSMANS 2008. Accessibility and utilisation of delivery care within a Skilled Care Initiative in rural Burkina Faso. Tropical Medicine and International Health 13, 44-52.

7. WHO 2008. Trends in Maternal Mortality: 1990 to 2008, Geneva, The World Bank.

8. WHO 2017. Tracking Universal Health Coverage: 2017 Global Monitoring Report. World Health Organisation.

9. ZINSZER, K. 2014. Determining health-care facility catchment areas in Uganda using data on malaria-related visits. World Health Organisation Bulletin. 